\title{
ANNOTATION
}

\section{Reading with Closed Eyes}

An important, and so far as we are aware, novel series of observations is contributed to the Canadian Medical Association Journal, of November, 1932, by A. H. Pirie, B.Sc., M.D., of Montreal, under the above title.

The point is that print or pictures can be seen with closed eyes when the eyes are properly prepared to receive the appropriate stimulus. This occurs when the X-rays are used. The method is simple. The observer must remain in total darkness for at least ten minutes. At the end of that time he will be able to see light when the X-rays strike his eyelids. After twenty minutes in the dark he will be able to read printed letters and to see pictures with the technique described below. A crystalline lens in the eye is not essential, for an aphakic patient was able to see and read as clearly as any other of the cases tested whose lenses were still in situ. When the aphakic patient tried to read the letters with his spectacles on, fluorescence occurred and vitiated the result. All glass fluoresces and Pirie draws the extremely practical conclusion that the method he describes may be of great service in cases of injury where minute fragments of glass are embedded in the deeper parts of the eye. Such bits may throw very little shadow on a photographic film and yet might fluoresce under the $\mathrm{X}$-rays sufficiently for the surgeon to see them. Simple diagrams show the method in use. The X-ray tube sends rays to the retina and in their path a lead letter " $T$ " is placed touching the closed lids. The retina sees light except where the shadow of the " $T$ " protects it from the rays. This shadow of the " $T$ " is upright on the retina and not reversed; the brain receives the message contrary to what it experiences by ordinary vision. Stereoscopic vision can be obtained by presenting stereoscopic pictures pricked in a lead treatment sheet to each eye and moving them about till the effects fuse. Metallic foreign bodies can be made to cast their shadows on the retina. The patient must be kept in total darkness for twenty minutes. If the foreign body has already been exactly localized, the patient will localize it in the same position, but turned from right to left and from above down.

If, therefore, the foreign body be localized in the lower nasal quadrant the patient will see it in the upper temporal quadrant. A brass grid with a central cross and two circles placed in front of the eye helps to make the localization more exact. When a foreign body lies inside the eye it only casts one shadow and the patient sees it as single; when it lies outside the eye it may cast one or 
two shadows; if the patient sees it double it is a proof that the foreign body lies outside the globe. (This assumes that not more than one foreign body is present in the globe.) A damaged area in the retina is recognized by the patient as a black spot. The blind spot can only be recognized by using weak X-rays; with rays of the ordinary strength its presence is lost in the brilliant field of illumination just as the stars are invisible when the sun is overhead.

The field of vision can be mapped out by using the grid; and this obtains in cases with dense opacity in the media.

When a solid spinning-wheel provided with a single hole is looked at by this method the individual flashes of the X-ray tube can be seen, but the impression gained is that the wheel is rotating in a direction opposite to its real motion.

There would appear to be a distinct field of usefulness in ophthalmology for this addition to our armamentarium.

\section{INTERNATIONAL OPHTHALMOLOGICAL CONGRESS}

\section{Madrid, April 16-22, I933}

THE National Committee of the International Ophthalmological Congress at Madrid have hired the Palace Hotel in which all the official meetings will take place. The Management of the Hotel are giving special terms to members of the Congress ; single rooms, with private bath-room, from 22 ptas. for an inside room to 35 ptas. for an outside room. Double rooms from 32 to 60 ptas. The meals will come to a total of 25 ptas. with 10 per cent. for service added to these rates. The present value of the peseta is 41 to the $£$. We understand that numerous reservations have already been made.

The first-class return fare to Madrid by Paris and Irun is 17 guineas, and for second-class $£ 13$ 5s. 11d. In addition, there will be the cost of reservation of seats in the pullman or in the Golden Arrow, and the price of sleeping-berths-first-class Paris to Irun $£ 3$ 7s. 2d.; second-class £2 11s. 4d. The total cost, therefore of the first-class return ticket with sleeping berths will be approximately $£ 2 \tau$ and of the second-class return ticket $£ 20$. Arrangements are, however, being made to secure special reduction of these rates on production of vouchers. The amount of this reduction has not yet been definitely ascertained, but the Southern Railway and probably the other British railways will reduce their return fare to approximately a fare and a third, on production of a voucher, and the French and Spanish railways have agreed to a reduction of 40 per cent. It is not yet certain whether that reduction will be available by the trains de luxe. 